\title{
O ESPÍRITO HERMENÊUTICO NAS CONSTRUÇÕES DISCURSIVAS SOBRE O ÍNDIO
}

\author{
THE HERMENEUTIC SPIRIT IN CONSTRUCTION \\ ON THE INDIAN DISCURSIVE
}

\author{
VANessa dos Santos Milder ${ }^{1}$
}

Recebido em: 09/07/2015 Aprovado em: 26/05/2016

\section{RESUMO}

O presente estudo tem como objetivo realizar uma sistematização de elementos e/ou características observáveis em determinadas obras históricas e etno-históricas, as quais compõem o quadro de produções historiográficas concernentes ao tema indígena no Brasil e em países vizinhos (Paraguai, Uruguai e Argentina). Tais elementos, de caráter historiográfico, dizem respeito, sobretudo, à discursividade e à construção dos textos, podendo ser observados a partir do pano de fundo que ritmiza as escolhas dos autores desses textos. Assim, busca-se uma reflexão acerca de alguns momentos observados no contexto historiográfico, em que o indígena passa de uma inexistência à protagonista de sua história, fato possível devido ao deslocamento ocasionado pelo olhar e pelas perguntas realizadas por pesquisadores (historiadores e antropólogos). Paulatinamente, as noções padronizadas oriundas de analogias comportamentais problemáticas (do final do século XIX e início do XX - que permeiam o entendimento das culturas de diferentes pontos da Terra) são substituídas pelas noções de agency, história e práticas culturais, objetivando uma reorientação de nossas questões, deslocando processos que não compreendemos e que queremos explicar historicamente e nos convidando a revisar como entendemos a relação entre causa e efeito. A construção discursiva sobre o indígena na historiografia está atravessada por fatores subjetivos, os quais se relacionam com posições teórico-metodológicas e filosóficas definidas pelo período e contexto em que o historiador está inserido. A partir da observância de tal fator, quando suas obras são analisadas na atualidade, é possível clarificar a maneira pela qual fontes, referências, pessoas e projetos políticos estão entrelaçados e como esses elementos são transformados em narrativa ou discurso.

Palavras-chave: Indígena; Historiográfico; Construções Discursivas.

\section{ABSTRACT}

The present study aims to conduct a systematization of elements and / or characteristics observable in certain historical works and ethno-historical as which make up the historiographical productions board concerning the indigenous issues in Brazil and in neighboring countries (Paraguay, Uruguay and Argentina). Such elements of historiographical character, Respect say, above all, the discourse and the construction of texts, can be observed from making cloth background that ritmiza choices authors these texts. So search is a reflection about some observed moments not historiographical context, in which the indigenous goes from a lack the protagonist of your history, suit possible because the caused hair offset look and for questions conducted by researchers (historians and anthropologists). Gradually, as standardized notions arising from problematic behavioral analogies (see last century XIX and early XX - What permeate the different understanding of cultures earth points) are replaced by agency notions, history and cultural practices, aiming a refocusing of our questions, shifting processes that do not understand and that we want to explain historically and inviting us to review how do we understand the relationship between cause and effect. The discursive construction about Indian historiography crossed is in subjective factors, which relate to theoretical and methodological positions and philosophical hair defined period and context in what the historian is inserted. At from the observance of such a factor, when their works are analyzed at present, and possible to clarify the way sources, references, people and political projects are intertwined and how these elements are processed in narrative or speech.

Keywords: Indigenous; historiographical; Discursive constructions.

${ }^{1}$ Mestranda em História pela Pontifícia Universidade Católica do Rio Grande do Sul (PUC-RS), Brasil. E-mail: vanessamilder@gmail.com. 
1 A construção acadêmica sobre o índio nos diferentes momentos historiográficos

A prática de historiar é, muitas vezes, marcada pelas intenções dos sistemas sociais, os quais são direcionadores de ideologias coercitivas para a construção social de um mundo onde problemas e soluções ou perguntas e respostas devem compor harmonicamente um fluxograma de acordo com as relações estabelecidas por grupos que selecionam o que deve ser memorável e o que deve ser descartado. Cabe aqui ressaltar que as conjunturas nas quais pesquisadores e fontes interagem para criar ou reconstruir histórias estão entrelaçadas dentro de uma estrutura em que muitos processos de transição estão ocorrendo, seja no campo das Ciências Sociais, seja no campo das Ciências Exatas. Portanto, elementos e vieses podem, por vezes, entrecruzarem-se nas frágeis linhas que separam uma perspectiva de outra.

Nesse contexto, como observado no texto do historiador Guillermo Furlong, "Indigenas y mestizos", do livro "Historia social y cultural del Rio de la Plata: 1536-1810 - El transplante social", publicado em 1969, percebe-se que há uma persistência na abordagem teórica e no trato com as fontes, que desloca o historiar de uma época, fazendo com que adentre um período e um contexto historiográfico subsequente do processo histórico. O Furlong de 1938 ("Entre los Abipones del Chaco") organiza o seu discurso de maneira a pontuar uma diversidade de temas, coletados nos documentos oficiais (do século XVIII principalmente), que foram escritos pelos padres jesuítas da Companhia de Jesus², como Martin Dobrizhoffer, Domingo Muriel, Jose Brigniel, Joaquin Camaño, Jose Jolis, Pedro Ruan Andreu, Jose Cardiel e Vicente Olcina.

Embora Furlong tenha publicado duas obras (já mencionadas), que são consideradas por alguns historiadores

${ }^{2}$ Ordem religiosa que aplicou um projeto reducional entre os indígenas que habitavam a América do Sul - nesse caso específico, a região do Chaco argentino. uma referência para a história indígena e jesuítica, o autor utiliza em sua construção discursiva um posicionamento que o torna um "continuador" do discurso expresso nos documentos oficiais, embora não os cite. Dessa maneira, ele "amansa" o processo de colonização que se estabeleceu na América espanhola nos séculos XVI, XVII e XVIII quando procura justificar as ações da Coroa Espanhola durante a catequização dos indígenas - os Abipones -, defendendo as Reduções de Índios e as encomiendas sob a justificativa dos bons objetivos dos Reis da Espanha para o apaziguamento e o desenvolvimento da região do Chaco argentino.

A problemática aqui colocada não é necessariamente desconfortável para todos os historiadores. Consiste, pois, na heurística e na hermenêutica do trato com as fontes. Cabe realizar, diante disso, algumas considerações sobre os estudos de Wilhelm Dilthey (18331911) a propósito da hermenêutica e das investigações históricas (Hughes, 2002). Segundo Hugues (2002, p. 86), Dilthey sustenta que "nossa compreensão de nós mesmos e de outros [...] não principia com descrições psicológicas, mas com a interpretação das expressões humanas". Portanto, o que está em voga nesse momento adentra o mundo teórico-metodológico da historiografia nos seus diferentes períodos, os quais estão indissociavelmente relacionados com posições filosóficas dos indivíduos que escrevem e interpretam discursos dentro das lógicas vigentes.

Compreender os escritos de Furlong dentro de uma lógica que tem por base o "círculo hermenêutico" proposto por Dilthey, em que o "conhecimento dos atos de um agente histórico germina a compreensão de um período ou de uma era e isso, por sua vez, aumenta nossa compreensão dos atos desse indivíduo e assim por diante" (Hugues, 2002, p. 89), podendo ser uma das maneiras de entender suas sistematizações. Compreensões sobre como os discur- 
sos são construídos estão relacionadas com o entendimento da das escolhas que estruturam a narrativa elaborada. Contudo, a interpretação de fato de um processo histórico pode e deve ser revisada, rebatida e reinterpretada em qualquer tempo ou de qualquer tempo. Portanto, não se trata de apontar críticas à construção discursiva encontrada na produção historiográfica, mas de compreender o historiador no seu tempo, atentando às constantes revelações da história dos indivíduos que viveram no passado, agiram e fizeram suas histórias. Entretanto, como aponta Wittmann (2014, p. 50), "cabe ao pesquisador [...] não confundir documento histórico com história, e analisá-lo como tal. Fontes são históricas [...] porém não são História. Estas somos nós os encarregados de contar".

Com base nessa relação entre contar histórias e utilizar fontes, observa-se que Furlong, dentro das idiossincrasias de um período, não ampliou as possibilidades interpretativas dos documentos oficiais da Companhia de Jesus, o que tornou o seu discurso um apanhado de generalizações e descrições que não dão conta de explicar a agência indígena, observada sob a perspectiva do atual paradigma da história indigenista em que estamos inseridos.

Segundo Aróstegui (2006, p. 361-362), o foco dos pesquisadores (do século XIX) não era "explicar o que ocorria na história" de forma precisa, mas organizar os dados. Portanto, em um primeiro momento, os historiadores objetivam uma organicidade dos documentos. Essa afirmação de Aróstegui dá suporte para que seja possível entender os elementos contemplados pelos historiadores pioneiros, embora nos seus escritos os agentes sejam os jesuítas, e a história contada recaia sobre as Missões Jesuíticas, e não sobre o indígena.

Assim, o historiador Aurélio Porto no I e III capítulos - denominados, respetivamente, de "Primitivos habitantes do Rio Grande do Sul" e "Florescimento dos Sete Povos", respectivamente - de sua obra intitulada "História das Missões Orientais do Uruguai", publicada em 1943, utiliza a História como instrumento, manipulando-a sob uma perspectiva política. Segundo Ieda Gutfreind (1992), em 1920 a tendência do discurso historiográfico sulino insistia no sentimento de brasilidade de seus habitantes, motivo pelo qual a defesa do sistema federativo atuou politicamente nos discursos dos historiadores gaúchos, especificamente dos que pertenciam ao Partido Republicano Rio-grandense.

Dentro dessa conjuntura, em 1920, os historiadores gaúchos, tanto de matriz lusitana quanto de matriz platina, destacaram a questão geográfica e a situação de fronteira vivida pelo Rio Grande do Sul. Tal fato pode ser percebido no discurso do historiador Aurélio Porto, no texto já mencionado, em que se estabelece uma divisão etnográfica dos grupos indígenas em províncias raciais distintas, esboçada pela primeira vez em um mapa organizado por Porto e intitulado "Mapa das Províncias Etnográficas no Território do Rio Grande do Sul".

A preocupação de Aurélio Porto com a questão territorial é percebida por meio da correlação entre o contexto em que o texto é construído e os elementos textuais relacionados às localizações específicas (indicadas por latitudes e longitudes exatas) de reduções jesuíticas, postos indígenas, cidades ou vilas que estavam em desenvolvimento. $\mathrm{O}$ ensaio sobre a classificação aborígene estabelece a divisão dos grupos indígenas em Grupos Raciais (Gê ou Mbaya), Ramos (Gê $=$ Autóctones, Guaianazes ou Guaranizados; Mbaya $=$ Guaicurús do Sul), Nações (Gê = Caaguá, Ibirajara e Tape; Mbaya = Chaná) e Tribos ou Parcialidades (Gê = Caaguarás, Caamoguaras, Caatiguaras, Tapes, Arachanes, Caroguaras etc.; Mbaya $=$ Guenoas, Chanás, Charruas, Minuanos, Mboanes e Iarós). Essas divisões e subdivisões étnicas, por sua vez, serão enquadradas dentro das Províncias Etnográficas (Ibiaça, Tape e Uruguai). 
A esse respeito, Porto (1943, p. 28-29) afirma que "[...] o atual Estado do Rio Grande do Sul estava em grande parte povoado por indígenas oriundos de três grandes grupos raciais perfeitamente distintos [...]" e que os dados necessários para esse esboço provêm de documentos oficiais dos jesuítas espanhóis e de outros trabalhos. Nesse período historiográfico, o pesquisador está praticamente "preso às fontes", tornando-se refém destas, o que resulta em narrativas que são apelativas e que reforçam o discurso jesuítico (oriundo dos documentos).

Além de reforçar o discurso jesuítico, Aurélio Porto constrói narrativas que colocam o indígena em uma escala evolutiva. $\mathrm{O}$ autor possui uma grande preocupação com a história genealógica dos grupos indígenas - característica historiográfica do período que se inicia no final do século XIX, no contexto brasileiro (Schwarcz, 1996) -, a qual é corroborada pelas suas referências bibliográficas: "Genealogia Paulista" (1903), de Leme Silva; "História Genealógica de Portugal", de D. Antonio Caetano de Souza; "Origem provável das diversas raças que povoaram o território pátrio" (1918), de Antonio da Silva Neves; e "Genealogia riograndense" (1937), de Jorge Godofredo Felizardo.

Nesse cenário de desenvolvimento científico do século XIX e início do século XX, o mundo classificatório não se restringe ao reino botânico e animal, pois as comunidades humanas são pensadas com base nas noções de determinismo ambiental, adaptação, mudança, temporalidade, complexidade, simplicidade etc. Tais noções faziam parte do espírito da época, quando se estabeleciam parâmetros de comparação entre uma sociedade e outra e se observavam as capacidades cognitivas e tecnológicas dos grupos humanos, a fim de definir e explicar as diferenças do desenvolvimento do corpo humano em diferentes lugares do mundo, trazendo consigo a ideia cristã de degeneração, comum no período.
Porto reforça, baseado em escritos de pesquisadores (Lund e Ameghino), que os grupos humanos encontrados no território que vai do continente Sul até o Rio da Prata pelos jesuítas durante o período colonial eram descendentes de povos que subjugaram os "legítimos autóctones" - estes poderiam, inclusive, ser contemporâneos dos "homens das cavernas". Dessa maneira, o autor constrói um edifício de afirmações que objetivam situar e classificar os indígenas conforme os estudos da Antropologia Física do período (dolicéfalos ${ }^{3}$ e braquicéfalos ${ }^{4}$ ), considerando-os oriundos de indivíduos que habitaram a região platina no período "arcaico" pré-colonial.

A hermenêutica utilizada pelos historiadores consiste em uma reconstrução, que, ao ser entendida, permite reconstruir o processo discursado tão bem quanto seu autor ou como se "eu fosse o autor"s (Grondin, 2012, p. 7).

${ }^{3}$ Indivíduos que têm o crânio com a largura menor que o comprimento. ${ }^{4}$ Indivíduos que têm o crânio com a largura igual ao comprimento.

${ }^{5}$ Para compreender a aplicação hermenêutica no texto de Guillermo Furlong, intitulado "Entre los Abipones del Chaco", de 1938: "Fué certamente um grave error de los primeiros conquistadores el no haber sabido los médios de ganarse a estos indígenas, antes haberlos exasperado castigándolos por crímenes que no habían cometido" (Furlong, 1938, p. 71). Neste trecho, Furlong refere-se aos Abipones, mencionando sua "Rapidez em sus acciones de guerra", o que demonstra uma tentativa por parte de Furlong, neste discurso, de tentar compreender bem as ações bélicas dos Abipones, com relação aos Mocobíes e Tobas (que tinham habilidades bélicas inferiores), pois "no haber sabido los médios de ganarse a estos indígenas" é apenas mais uma estratégia ou um mecanismo de cooptação que trabalha a favor da redução religiosa. Trata-se de uma crítica sobre a que trabalha a favor da redução religiosa. Trata-se de uma critica sobre
falha do processo coercitivo. Esse tema pode ser trabalhado de maneira a realizar um reforço do discurso jesuítico, como o faz Furlong, ou a partir de uma nova perspectiva (Nova História Indígena - sobre a falha do sistema coercitivo e as diferentes agências, indígenas, espanholas ou jesuíticas, neste caso). No trecho a seguir, o processo histórico é contado como se o próprio Furlong fosse o autor dos discursos de suas fontes e referências bibliográficas, não no sentido expresso e literal de plágio, mas no sentido do entendimento de como os fatos aconteceram ou, melhor, de como não criticar e repetir discursos, a exemplo das encomiendas: "Si em como não criticar e repetir discursos, a exemplo das encomiendas: 'Si em
1926 y en 1932 que las llamadas 'encomiendas', esto es, la césion de un grupo de indios que habrian de trabajar em beneficio del hombre blanco, y éste em retorno les habría de imbuir de la cultura europeas, habían sido poco menos que un criemen, y considerábamos a los jesuitas como los heraldos de esa campaña de libertad en prol del indígena, hoy somos de opinión muy diversa. Los jesuitas extremaron las cosas y proclamaron como um mal general lo que era solamente particular, y em vez de poner los médios para acabar com el abuso, acabaron com el uso, síendo así que éste era entonces el mejor que se podia arbitrar y los abusos eran casos aislados y corregibles. El medio estaba em cortar algumas ramas, pero no el árbol todo" (Furlong, 1969, p. 21). Uma analogia sobre o ponto de vista de Furlong (baseada rigidamente no ponto de vista do discurso ocidental, oficial e documental) pode ser a passagem do "Sermão do Espírito Santo" (1657), de Antônio Vieira, associado ao seu uso no texto de Eduardo Viveiros de Castro (2002), intitulado "O mármore e a murta: sobre a inconstância da alma selvagem", que trata do problema da descrença no século XVI brasileiro: "É só desta maneira, trabalhando contra a natureza século XVI brasileiro: "E só desta maneira, trabalhando contra a natureza
do tronco e humor das raizes, se pode conservar nestas plantas rudes a forma não natural, e compostura dos índios" (Castro, 2002, p. 184). Ao expressar que há uma diversidade de opiniões sobre como a encomienda é pensada dentro do processo histórico no período historiográfico que vai do início dos anos 20 até aproximadamente os anos 60 , trazendo implícita 
Essa operação hermenêutica provém de Schleiermacher (1768-1834), segundo Grondin (2012). Dilthey (1833-1911), conhecedor da obra de Schleiermacher, com o objetivo de fundar a especificidade metodológica das Ciências Humanas, trata de especificar a hermenêutica "como 'a arte da interpretação das manifestações vitais fixadas por escrito"” (Grondin, 2012, p. 34, grifo do autor).

Com o intuito de "conter a deriva constante do desentendimento", Schleiermacher infere que a reconstrução de um discurso ocorre pelo bom entendimento de seus elementos, como se quem analisa fosse seu autor (Grondin, 2012, p. 28). Nesse sentido, o espírito hermenêutico reducionista da época interpela e permeia a construção narrativa e a narração, de maneira que um olhar historiográfico e um entendimento pertencentes ao "senso comum" da história sejam ambos percebidos como entendimento, pois "entender o discurso de início tão bem e, posteriormente, melhor que seu autor" (Grondin, 2012, p. 28) é um transplante realizado por Schleiermacher que marca o início das preocupações acerca de uma hermenêutica para a ciência histórica (com posterior estudo de Dilthey), tendo como pano de fundo a máxima utilizada por Kant, que, por sua vez, será o princípio geral de Schleiermacher: "Nada de surpreendente há em se poder entender Platão melhor do que ele mesmo se entendeu, inclusive porque ele próprio determinou insuficientemente seu conceito" (Grondin, 2012, p. 2829). Nesse sentido, as marcas iniciais das preocupações interpretativas dos teóricos estigmatizam também as construções discursivas dos pesquisadores.

Ao compreender as formas de construção narrativa pelo viés hermenêutico dos autores ou da época em que estes estão inseridos, é importante

a noção de escolhas para a construção teórico-metodológica dos processos históricos, no texto de 1969, "Indigenas y mestizos", pertencente à obra "História social y cultural del Rio de la Plata: 1536-1810 - El transplante social", Furlong menciona: "Ésa fué lá única causa real y efectiva de la disminución de los indígenas entre nosostros, ya que, fuera, el trato de los españoles y criollos con los indígenas no pude ser más callabaresco" (1969, p. 1920). Percebe-se, assim, uma reconstrução que reforça e adula o processo discursado pelos jesuítas. atentar para o fato de que se trata apenas de uma das maneiras, entre as várias possíveis, de entender como ocorreu a construção dos textos que são as referências bibliográficas sobre o tema indígena no presente, não somente em escala micro, mas também em uma escala macro. As construções acerca de como aconteceram os processos históricos não ocorrem apenas a respeito do tema indígena, mas também de todos os temas, pois a construção do discurso é vista como um processo histórico de longa duração, oriundo da historiografia que se transforma e ganha novas perspectivas vindas da própria revolta interior da História e das agregações antropológicas, arqueológicas, sociológicas e filosóficas desse "pensar". Tal processo, que emerge e que é anterior à escrita, convida a questionar não somente a razão pela qual a cultura muda, mas também o que faz as pessoas mudarem e como elas negociam dentro do processo histórico, sejam elas agentes ou (re)construtoras de histórias. Analogias comportamentais e estudos de práticas culturais, principalmente os que contemplam a ênfase na prática das pessoas, elevam a explicação histórica, exigindo, contudo, uma reformulação das velhas perguntas (e quem sabe das novas também) ou uma proposição de revisões para coletar dados que respondam aos novos questionamentos. De maneira não tradicional e não confortável, seria possível não fazer perguntas específicas aos documentos, mas deixar que as próprias linhas preenchidas com palavras ofereçam uma direção ao problema, problema que também é problemático, porque pode estar ainda não revelado. Dessa forma, retirar a "grade" colocada diante do fato, do documento ou da evidência, e não realizar uma história repetida, tem sido um dos grandes desafios da atualidade.

Portanto, entender a argumentação, o encadeamento e o raciocínio dos autores é compreender a sintonia da construção histórica, pois isso diz 
muito sobre as escolhas heurísticas e hermenêuticas. Sob essa perspectiva, é possível notar que a hermenêutica aqui é agenciada pelos autores que pensaram sobre o entendimento hermenêutico em um período emergencial geral, mas também em um momento marcado pela virada existencial proposta por Heidegger e por outros grandes pensadores do processo histórico hermenêutico e de sua aplicação na História e nas áreas afins.

Para pensar a presença do indígena na construção acadêmica de um segundo momento, ou de maneira contínua ao primeiro, em que a presença indígena inexiste, será utilizada a construção narrativa e discursiva de historiadores, do antropólogo Alfred Métraux e de pesquisadores que possuem uma formação integralizadora nas Ciências Sociais, conforme as antigas escolas de estudos da grande área das Sociais e Humanas, como é o caso de Maxime Haubert. Haubert evoca em seu texto "Una conquista espiritual", presente na obra "La vida cotidiana de los indios y jesuitas em las misiones del Paraguay" (1967), um discurso do Padre Antonio Ruiz de Montoya, pertencente ao livro "Conquista Espiritual del Paraguay" (1639), que é uma fonte documental histórica muito utilizada (e às vezes mal utilizada), para a reconstrução dos processos históricos coloniais, concernentes ao contato com os indígenas da região platina e à sua catequização. Neste discurso introdutório, Montoya refere-se, segundo Haubert, a "[...] una juventud vivida en el desenfreno, en la víspera de un largo viaje en el que temía perder la vida y la salvación [...] llamado a la vocación misionera" (Haubert, 1967, p. 26). Esse espírito discursivo jesuítico incorporado ao texto de Haubert demonstra o ritmo textual de "Una conquista espiritual" e "Los nuevos brujos", um ritmo que é tocado pelas mãos divinas literalmente, tanto para os jesuítas quanto para Haubert.

Maxime Haubert ampara-se em um discurso argumentativo e defensivo, que evidencia a agência jesuítica em meio às provações encontradas durante os séculos XVI e XVII nos territórios que vão desde Assunção (Paraguai) até as áreas próximas aos Rios Paraná e Uruguai. Nesse sentido, a relação estabelecida entre Haubert e as fontes é bem estreita. Esses dois elementos, pesquisador e fonte de pesquisa, representam espelhos que se confrontam sem se questionarem, pois pretendem perpetuar a silhueta da coisa que está posta à sua frente. Essa coisa assume um perfil idêntico, em que a única diferença visível consiste na mão de quem segura o espelho -, nesse caso, de quem escreve e no tempo e nos locais em que essas pessoas que escrevem estão situadas.

$\mathrm{O}$ texto de Haubert é riquíssimo em detalhes e minúcias, todas elas encontradas tal e qual nas fontes documentais. Há, assim, uma infinidade de detalhes, como nomes próprios: Dobrizhoffer, Cataldino, Paucke, Lorenzana, Artigas, Du Toict, San Martin etc. Esses nomes são de pessoas que agiram durante o processo colonial, seja contando a história dos indígenas a seus modos, seja atuando como agentes na sua história e na história dos outros.

Antes de abordar outros detalhes encontrados nos escritos de Haubert que se referem ao índio, faz-se necessário compreender a obstinação jesuítica na travessia atlântica até os "selvagens". Assim, o ritmo textual é cadenciado pelo não questionamento do pesquisador às fontes. Um dos trechos que anunciam alguma posição mais efetiva de Haubert consiste na exaltação messiânica depois de transcorrido muito tempo. Embora o autor não problematize as fontes documentais e a agência indígena, ele faz uma contribuição à popularização da história das Missões Jesuíticas, uma das características do momento político em que está inserido.

Alfred Métraux (1928), ao apresentar a "Civilização material das tribos tupi-guarani”, constrói a história das técnicas a partir de fontes disponíveis, enquadrando a cultura material dentro de 
um modelo difusionista, segundo o qual, a partir de um centro irradiador (a zona nuclear), a cultura é "bombeada" para diversos locais periféricos. Ainda que esse modelo difusionista já esteja defasado atualmente, a obra de Métraux tornou-se uma espécie de tesouro da etnografia devido à riqueza de informações e ao detalhamento da cultura material encontrada no território dos tupi-guarani.

Assim, a discussão ora proposta sobre essa obra ganha destaque por ter se tornado uma fonte recorrente e que influencia a produção historiográfica e a literatura arqueológica, conforme indicia Noelli (1996, p. 18): “As migrações históricas estudadas por Métraux (1927), em que se apóia a maioria dos pesquisadores, representam basicamente os movimentos de fuga da pressão europeia". Segundo Noelli (1996, p. 19), Métraux "fundiu o modelo radial com o da expansão de sul para norte através da costa atlântica".

Moysés Vellinho (1964) e Moacyr Flores (1983) constroem narrativas permeadas pelas questões de identidade e formação do gaúcho. Essa postura política está relacionada ao povoamento, às fronteiras nacionais e à produção de manuais que explicam a história das Missões Jesuíticas de uma maneira factual, sem críticas às fontes utilizadas, assumindo, assim, posturas passivas diante das fontes e ativas diante do contexto em que eles - os historiadores estão inseridos. Moacyr Flores, em "As reduções e o sistema colonial espanhol", texto pertencente à obra "Colonialismo e Missões Jesuíticas" (1983), opta por uma maneira científica ${ }^{6}$ de organização, que confere à leitura uma estruturação lógico-matemática.

De matriz historiográfica lusitana, Moacyr Flores faz um contraponto à visão de Moisés Vellinho sobre a lenda, o

\footnotetext{
${ }^{6}$ No trecho "A bibliografia divide-se em dois grupos: um que tece louvores ao trabalho dos missionários e outro que condena a segregação indígena, apontando o Estado Teocrático como uma realidade em busca da conquista do universo. Os inacianos constituíram uma república teocrática? Quais os objetivos do governo temporal das missões? Estas perguntas serão respondidas com o auxílio da documentação de Angelis e de alguns autores que versaram sobre o tema" (Flores, 1983, p. 15), o autor demonstra como faz História: Problemas $>$ Fatos $>$ Perguntas.
}

mito e a história de Sepé Tiaraju, ao mesmo tempo em que busca abrilhantar a história ultramarina com a defesa do projeto português na América ${ }^{7}$. A preocupação da historiografia recai, assim, sobre dar conta de explicar a história das Missões Jesuíticas, em sentido unilateral por "suele documentar su origen, sus eventuales modelos, su legislación, las vicissitudes de su implantación, sus diversas formas, [...] su consolidación y, por fin, su desintegración" (Melià, 2004, p. 203-204).

A história dos indígenas, sejam eles guaranis ou não, fora construída nesse momento historiográfico e aparece de "manera subsidiaria y dependiente" (Melià, 2011, p. 81): "há pessoas Guarani na história, mas não há história Guarani" (Melià, 2009, p. 129). A hermenêutica nesse período permanece com o espírito que quer "reconstruir a gênese de". Reconstruir um processo histórico está vinculado ao sentido que "eu" atribuo, estabelecendo um "processo pelo qual conhecemos um interior pelo auxílio de sinais percebidos desde o exterior por nossos sentidos" (Grondin, 2012, p. 34-35).

Bartomeu Melià, linguista e antropólogo, é responsável por uma contribuição de valor inestimável para a etno-história. Para adentrar um terceiro momento historiográfico sobre a construção da história indígena, "O outro próximo", será utilizado o texto "El modo de ser Guaraní en la primera documentación jesuítica", presente na obra "El Guaraní Conquistado y Reducido: ensaios de etnohistoria", de 1988, do mencionado autor.

Utilizando a documentação jesuítica, Melià lança a flecha da projeção que abre espaço para uma revelação, o "modo de ser" Guarani, bem como para uma compreensão da realidade cultural dos indígenas, levando em consideração que o processo reducional é apenas uma variante que ocorreu na história. Assim,

\footnotetext{
7 "A mestiçagem se processou com a incorporação de elementos culturais indígenas na cultura luso-brasileira que era a mais forte tecnologicamente e a mais abrangente. Criou-se no Rio Grande do Sul uma sociedade de guerreiros por causa das lutas de fronteiras com os espanhóis e seus descendentes, durante quase duzentos anos. Sepé Tiaraju, o santo-guerreiro que morreu defendendo sua terra, foi adotado como um símbolo popular pelos rio-grandenses através de um processo de contato de duas culturas" (Flores, 1983, p. 101).
} 
o que é posto não é a história das Missões Jesuíticas, mas a história dos indígenas e as suas ações durante o processo colonial. Em 2011, o autor afirma que "a lo largo de esa historia de 160 años es la sociedade guaraní, certamente transformada pero com su propia identidad, la que está en acción" (Melià, 2011, p. 88).

A questão colocada por Melià em sua obra (1988) faz parte dos questionamentos que surgiram a partir dos anos 80 na historiografia que se debruça sobre a história indígena: "¿pueden extraerse datos suficientes y apropriados para la reconstrucción de la realidade cultural guaraní previa a los primeiros contatos coloniales o por lo menos concomitante com ellos?" (Melià, 1988, p. 96). Considerando-se um conjunto de dados extraídos de documentos oficiais da Companhia de Jesus, como a carta do Padre Alonzo Barzana e Juán Sebastián, de 1594 (publicada em Furlong, 1968), e o texto "Conquista Espiritual", do Padre Antonio Ruiz de Montoya, de 1892 [1639], Melià procura utilizar os elementos que constam nessas documentações, tais como religião, governo, costumes, vestimentas, cantos e ritos dos Guarani, não de maneira sistematizada, como até então os pesquisadores faziam para criar esboços da cultura Guarani, mas como prática cultural e política desses indígenas face a um sistema que está se introduzindo no mundo Guarani e que pretende mudar esse mundo.

A partir dos dados que se revelam nas páginas dos documentos sobre a confrontação de duas culturas, a indígena e a ocidental, Melià trabalha de maneira a reconstruir uma realidade indígena, em que o pesquisador precisa atuar para que os detalhes e as reflexões sobre os documentos sejam percebidos de um ponto de vista não reducionista, embora o discurso (jesuítico) seja reducionista. Por isso, Melià afirma que "tal vez la clave hermenêtica más importante para abordar la lectura de la documentacion jesuítica es la que tiene em cuenta su "reduccionismo" (Melià, 1988, p.
97). O reducionismo opera quando a realidade é fragmentada e traduzida segundo as categorias do observador. Por essa razão, em um primeiro momento historiográfico, a realidade indígena entra em contraste "com el ideal de hombre político y humano [...] no se puede ler el discurso etnográfico missioneiro fuera de esta perspectiva" (Melià, 1988, p. 98). Isso demonstra o reforço dado ao discurso jesuítico nas primeiras sistematizações realizadas por historiadores, quando estes são reféns das fontes (já discutido anteriormente), indicando que os primeiros historiadores são afetados pelo reducionismo e pelos essencialismos jesuíticos.

Ao procurar categorias fundamentais para uma reestruturação semântica, os elementos da documentação jesuítica e da cultura Guarani atual possibilitam trazer noções do pensamento e da expressão do Guarani (históricos e atuais). Assim, Melià insere na história dos Guarani ${ }^{8}$ noções que pretendem ir além das sistematizações e lança traduções da realidade que encadeiam o ritmo cultural da ação indígena e de suas performances, inaugurando a noção de "modo de ser" - ñande reko - na historiografia, um dos carros-chefes que irá desencadear na história uma agência e um perspectivismo indígena, que serão daqui em diante massivamente utilizados para a reconstrução paulatina da história indígena.

Ao sugerir que uma possível "chave hermenêutica" seja necessária para a compreensão do reducionismo nos documentos oficiais, Melià demonstra sua preocupação com o entendimento discursivo no texto/documento do outro autor. $\mathrm{Na}$ virada existencial que Heidegger realiza na hermenêutica e na sequência, quando essa ideia fora explorada e expandida por teóricos como Bultmann, Gadamer e outros,

\footnotetext{
${ }^{8}$ Melià insere essa noção não de uma maneira existencial para os indígenas, porque essa noção é a maneira de ser do Guarani. Quem descobre algo somos nós, os pesquisadores. Essas descobertas são revelações para nós, porque estamos presos aos discursos repetidos. A história e agency indígenas estão nos documentos; quem não sabe interpretar e revisar sua maneira de historiar somos nós (sem generalizações).
} 
coincidentemente ou não, a noção de Dasein $^{9}$ é subjetivamente trabalhada.

Talvez essa noção não estivesse muito dissolvida no pensamento que era jogado para a compreensão dos estudos etno-históricos ou históricos, pois a hermenêutica deve se dissolver em determinado período ou em determinado local da prática historiadora e estar incorporada à nossa própria agência. Para Grondin (2012, p. 41), citando Heidegger, "a hermenêutica tem como tarefa tornar cada Dasein atento a seu próprio ser, comunicá-lo a ele, expulsar a alienação de si que assola o Dasein".

A hermenêutica com o viés existencial não está presa aos textos como a hermenêutica clássica, mas leva em consideração a existência de cada um. Dito isso, uma maneira de compreender o que está sendo proposto é que há uma libertação do Ser. Não, necessariamente, deve-se não utilizar essa hermenêutica para entender os textos, mas faz-se necessário compreender que "é preciso 'destruir' as interpretações que mantêm [...] seu estado de sonolência" (Grondin, 2012, p. 41, grifos do autor). A ideia de revelação e Ser trabalhadas por Heidegger para uma fenomenologia hermenêutica parecem estar de alguma maneira imbrincadas na perspectiva de Melià e dissolvidas na maneira de entender e construir seu discurso ${ }^{10}$.

Santos (1999) publica "Clastres e Susnik: uma tradução do 'Guarani de papel'”, em que propõe uma atenção à construção confortável do texto que se torna um clássico e à própria utili-

\footnotetext{
${ }^{9}$ Segundo Salanskis (2011, p. 23), "Tal é justamente a chave da denominação Dasein, que Heidegger usa para substituir o termo ordinário 'sujeito'. O Dasein é esse que é o aí, se é possível traduzir literalmente a palavra alemã. A denominação clássica sujeito enfatiza a ideia de um feudo inexpugnável da subjetividade, algo substancial e fechado em si mesmo, que, como tal, se opõe justamente ao que é estranho, exterior, genericamente chamado de objeto e reunido num mundo. Faz parte da perspectiva de Heidegger, desde o início, recusar o conceito desse face a face, declarando, ao contrário, que o sujeito se define como algo que encontra seu ai no mundo e que, nesse movimento, o sujeito-Dasein, na verdade, abre o mundo tanto quanto nele se situa. Se, em certo sentido, o Ser-no-mundo engendra o espaço e o mundo, também engendra o sujeito no sentido de um sujeito localizado, inserido" (grifos do autor).

${ }^{10}$ No sentido literal de trabalhar com o "modo de ser" do Guarani e em ${ }^{10}$ No sentido literal de trabalhar com o "modo de ser" do Guarani e em
sua metodologia de revelação desse modo de ser. Entre muitos exemplos que poderiam ser explorados sobre essa possível relação, será utilizado o seguinte trecho do texto "El modo de ser Guaraní em la primera documentacion jesuitica (1594-1639)" (1988, p. 97): “[...] En la confrontación los dos sistemas se juzgan mutuamente y, entrando em crisis, se revelan".
}

zação desse texto para a construção de outros textos. A utilização de notas de reforço e de citações clássicas torna o texto bem argumentado e justificado, porém a autora chama atenção para que se pondere sobre como os autores clássicos construíram suas ideias. A produção e a reprodução de um "Guarani de papel", feitas por um grupo de "aprendizes de feiticeiros", são realizadas sem um questionamento sobre a construção do discurso documental, pois "[...] o Guarani, parece ser assim porque Clastres ou Susnik disseram que era assim" (Santos, 1999, p. 205).

Santos realiza, nesse sentido, uma contribuição à construção historiográfica que busca especializar os estudos sobre o Guarani, ao pontuar questões problematizadoras no que concerne às traduções, pois "perde-se a precisão dos termos imaginados e expressos em guarani, por outros aproximados" (Santos, 1999, p. 206). Ao inferir sobre a expansão das fronteiras entre História e Antropologia, Santos (1999) deixa margem para que se adentre em um quarto momento da produção historiográfica sobre o indígena, que não necessariamente é uma ruptura, mas um processo historiográfico que vai sofrendo uma constate educação da atenção ${ }^{11}$ hermenêutica por parte dos pesquisadores do tema.

Schwarcz (1994), em seu texto "Entre amigas: relações de boa vizinhança", discute as relações entre História e Antropologia, relembrando inicialmente o historiador Marc Bloch com seu estudo pioneiro "Os reis taumaturgos" (1923), o qual afirmava que seu trabalho já "atentava para a natureza profunda dos fenômenos sociais"

\footnotetext{
"Segundo Ingold (2010, p. 23), "Assobiar uma melodia ou contar uma história que você ouviu no passado é como andar pelo campo ao longo de um caminho que você já percorreu antes em companhia de outra pessoa. Você se lembra à medida que vai andando, sendo que aqui 'ir andando' significa encontrar seu próprio caminho pelo terreno de sua experiência. Assim a melodia ou história é uma jornada realizada, ao invés de um objeto encontrado, e ter se lembrado do caminho já é ter chegado ao seu destin." Acrelita-se que Santos (1999) eduque nossa a ca a sobre questionar sua construção) e a revelação (jornada realizada = questiona e analisar a construção textual de um clássico/utilizar a sua experiência diante do que já deveria ter sido superado); "lembrar que isso deve ser pensado" e tentar fazer esse exercício para a construção de um novo dis-
} curso, já é um começo. 
(Schwarcz, 1994, p. 69). A diluição das fronteiras entre História e Antropologia permite a reflexão sobre estrutura e história. Para essa demonstração, Schwarcz apresenta a possibilidade dessa irmandade por meio dos trabalhos do antropólogo Marshall Sahlins e do historiador Robert Darnton. Cabe mencionar, aqui, o exemplo utilizado pela autora, para que seja possível compreender como as duas ciências se inter-relacionam, possibilitando um entendimento teórico sobre como se constrói ou se pensa a construção textual em que a perspectiva indígena é trazida à tona, como em "O mármore e a murta: sobre a inconstância da alma selvagem" (1992), de Eduardo Viveiros de Castro, perspectiva essa que almeja conhecer a filosofia indígena. Para isso, o autor realiza a análise de um sermão ("Sermão do Espírito Santo", 1657, de Antonio Vieira), o qual mostra que a história contada é viciada e repetida, pois o autor utiliza os elementos para a reconstrução da perspectiva indígena, e não da perspectiva jesuítica.

Dessa maneira, Castro (2002) reconstrói uma história antropologicamente pensada que culminará em uma mudança de expectativa entre os pesquisadores do tema indígena. A vingança, o mito, a antropofagia, a guerra e outros elementos tentarão ser pensados a partir da perspectiva indígena, da perspectiva do outro que não é ocidental. Demonstrar que os indígenas pensavam e que suas noções sobre determinados conceitos são diferentes das noções ocidentais é o ponto alto da discussão, alterando massivamente a história que até então era repetida por pesquisadores.

A Nova História Indígena, inicialmente, pode ser pensada a partir de uma afirmação de Wittmann (2014, p. 50): "Cabe ao pesquisador [...] não confundir documento histórico com história [...] Fontes são históricas [...], porém não são História”. Embora algumas considerações possam ser problematizadas no trabalho de Wittmann, "His- tória e religiosidade indígena: reflexões sobre um tema e um campo" (2014), a autora denuncia posições essencialistas ao passo que reivindica a compreensão de que os indígenas são protagonistas de sua história, e não apenas vítimas: "Apesar das imposições, as sociedades indígenas, diversas umas as outras, criam, interpretam agem e vivem" (Wittmann, 2014, p. 48). Tal reivindicação vem sendo alinhavada desde os escritos de Bartomeu Melià.

Quando Wittmann (2014, p. 50) afirma que foram os "brancos" que "nos deixaram registros sobre os quais podemos nos debruçar para reconstruir histórias", a autora em certa medida não abre espaço para se pensar a história indígena a partir de materiais escritos e produzidos pelos indígenas, como é o caso do trabalho que o historiador Eduardo Neumann (2007) apresenta (sobre os usos e as funções das formas textuais indígenas) e da própria cultura material trabalhada pelos arqueólogos. Da mesma maneira, quando a autora se refere a uma metodologia para abordar e retirar elementos que podem ser a "chave para a análise", afirma que "Uma leitura nas entrelinhas pode revelar, em meio aos discursos etnocêntricos, muitas surpresas não limitadas ao universo dos produtores do documento textual" (Wittmann, 2014, p. 51), quando, na verdade, os discursos unilaterais observados na documentação oficial do período colonial deixam expressamente clarificadas as controvérsias sobre o choque do contato entre indígenas e não indígenas. Nesse sentido, como afirma Melià, a "chave hermenêutica" é estar atento ao reducionismo contido no discurso desses documentos.

$\mathrm{O}$ perspectivismo ameríndio e a agency serão considerados pilares desse novo paradigma, com o intuito de demonstrar que o indígena é protagonista de sua história e, por vezes, um atuante, não sendo apenas um agente passivo na história de outros. Conforme a ideia norteadora de Pauketat (2001), ao refe- 
rir-se à reinterpretação de um processo histórico por meio da arqueologia, o foco da mudança foi a prática, colocada no contexto de uma tradição continuamente redefinida e reavaliada. Essa afirmação pode apontar para dois caminhos diferentes, que possuem uma lógica em comum: a mudança no entendimento ou na explicação histórica realizada por historiadores, arqueólogos ou outros pesquisadores, seja qual for o processo histórico em questão. Se for levada em consideração uma tradição cultural que não se dinamiza no decorrer no tempo, estar-se-á sujeitando a história a uma camisa de força composta de padrões e elementos culturais julgados como necessários a determinado grupo humano. Mas, se for considerada a prática das pessoas, suas ações cotidianas, os desvios, a criatividade e as fugas às regras, ter-se-á uma história diferente. É necessário, assim, prestar atenção nos detalhes das práticas humanas e no modo como as pessoas negociam mudanças dentro de seus grupos. A mudança na construção do discurso sobre o indígena ao longo do tempo ocorreu pela prática dos historiadores, que, constantemente ou pelo menos de tempo em tempo, reavaliam suas tradições historiográficas. $\mathrm{E}$, como não poderia deixar de ser diferente, ao avaliarem e redefinirem suas práticas e a aplicação de conceitos, repensam a história posta diante de nós.

\section{Considerações finais}

O exercício de pensar a construção da história do indígena, dentro da historiografia, implica pensar sobre entendimento e interpretação das pessoas que se debruçaram sobre o tema indígena e compreender o contexto histórico no qual quem escreve está inserido, o que dará suporte para pensar a "chave hermenêutica" proposta por Melià (1988), quando este alerta sobre o reducionismo nos discursos. Portanto, a chave hermenêutica é um elemento estrutural fundamental e talvez central nas reconstruções dos processos históricos. Ela está relacionada à maneira com que cada ser compreende e experimenta o mundo, bem como às premissas de uma ciência histórica que busca ser honesta na reconstrução a partir de discursos, sejam eles textuais ou materiais, de três grandes áreas: a História, a Arqueologia e a Antropologia.

\section{Referências}

1. ARÓSTEGUI, J. A pesquisa histórica: teoria e método. São Paulo: EDUSC, 2006.

2. FLORES, M. Colonialismo e missões jesuíticas. Porto Alegre: EST, 1983.

3. FURLONG, G. Entre los abipones del Chaco. Buenos Aires: Talleres Gráficos San Pablo, 1938.

4.

Historia social y cultural del Rio de la Plata: 1536-1810 El transplante social. Buenos Aires: TEA, 1969.

5. GRONDIN, J. Hermenêutica. São Paulo: Parábola Editorial, 2012.

6. GUTFREIND, I. A Historiografia Rio-Grandense. Porto Alegre: Ed. Universidade/UFRGS, 1992.

7. HAUBERT, M. La vida cotidiana de los indios y jesuitas en las misiones del Paraguay. Madrid: Temas de Hoy, 1991 [1967].

8. HUGHES-WARRINGTON, M. 50 Grandes Pensadores da História. São Paulo: Contexto, 2002.

9. INGOLD, T. Da transmissão de representações à educação da atenção. Porto Alegre, Educação, v. 33, n.1, p. 6-25, 2010.

10. MELIÀ, B.; TEMPLE, D. EI don, la venganza y otras formas de economía guaraní. Asunción: CEPAG, 2004.

11. MELIÀ, B. Escritos guarani como 
fontes documentais da história rio-platense, In: SUESS, Paulo; MELIÀ, Bartomeu; BEOZZO, José Oscar; PREZIA, Benedito; CHAMORRO, Graciela; LANGER, Protásio. Conversão dos Cativos: Povos Indígenas e Missão Jesuítica. São Bernardo do Campo: Nhanduti Editora, 2009.

12. El Guaraní Conquistado y Reducido: Ensayos de etnohistoria. Assunção: Biblioteca Paraguaya de Antropología, 1988.

13. Mundo Guaraní. Paraguay: Servilibro | BID - Banco Interamericano de Desarrollo, 2011.

14. NOELLI, F. S. As hipóteses sobre o centro de origen e rotas de expansão dos Tupi. São Paulo, Revista de Antropologia, v. 39, n. 2, 1996.

15. PAUKETAT, T. Practice and History in Archaeology: an emerging paradigm. Anthropological Theory. v. 1, n. 1, p. 73-98, 2001.

16. PORTO, A. História das Missões Orientais do Uruguai. Rio de Janeiro: Impr. Nacional, vol. 1, 1943.

17. SALANSKIS, J. M. Heidegger. [Coleção Figuras do saber]. São Paulo: Estação Liberdade, 2011.

18. SANTOS, M. C. "Clastres e Susnik: uma tradução do Guarani de papel". In: GADELHA, Regina (Org.). Missões Guarani: impacto na sociedade contemporânea, São Paulo: EDUC, 1999, pp. 205-219.

19. SCHWARCZ, L. M. As teorias raciais, uma construção histórica de finais do século XIX. O contexto brasileiro. IN: Raça e Diversidade/Lilia Schwarcz e Renato da Silva Queiroz (Org). SP: EDUSP, 1996.

20. SCHWARCZ, L. K. M. "Entre amigas: relações de boa vizinhança." Revista da USP, São Paulo, n. 23, p. 6875, 1994.

21. Vellinho, M. Capitania d'El -Rei: aspectos polêmicos da formação rio-grandense. Rio de Janeiro: Globo, 1964.

22. VIVEIROS DE CASTRO, E. A Inconstância da Alma Selvagem. São Paulo: Cosac Naify, 2002.

23. WITTMANN, L. T. "História e religiosidade indígena: reflexões sobre um campo e um tema". In: FLECK, Eliane Cristina Deckmann (Org.). Religiões e religiosidades no Rio Grande do Sul (vol. 3): manifestações da religiosidade indígena, São Paulo: Anpuh, 2014, pp. 47-68. 